\title{
Trabalhadores em Educação no Governo de Pernambuco: por um diálogo ativo
}

\section{Education Workers in the Government of Pernambuco: for an active dialogue}

\author{
Ana Claudia Dantas Cavalcanti*
}

\begin{abstract}
RESUMO
Com o aporte teórico em Habermas (2012) e através da perspectiva qualitativa e análise de conteúdo (BARDIN, 1997), nosso objetivo foi analisar como as diretrizes, que estavam presentes na concepção das políticas educacionais do governo de Pernambuco, foram construídas com o início da participação do Sindicato dos trabalhadores em Educação de Pernambuco (SINTEPE) na elaboração dessas políticas. As análises teóricas são articuladas com entrevistas semiestruturadas de representantes do SINTEPE. Este estudo revelou que a racionalidade sistêmica preponderava na correlação de forças com o SINTEPE para construir a política de educação no estado. Nesse sentido, a construção de políticas educacionais foi conduzida pela gestão gerencial em Pernambuco durante o período investigado.

Palavras-chave: Gerencialismo. Políticas Educacionais. Trabalhadores em Educação. Participação Cidadã.
\end{abstract}

\begin{abstract}
With the theoretical contribution in Habermas (2012) and through the qualitative perspective and content analysis (BARDIN, 1997), our objective was to analyze as the guidelines, which were present in the educational policies of the Government of Pernambuco, were constructed with the beginning of the Education Workers Union of Pernambuco (SINTEPE) participation in the elaboration of these policies. The theoretical analyzes are articulated with semi-structured interviews of SINTEPE representatives. This study revealed that systemic rationality prevailed in the correlation of forces with SINTEPE to construct the education policy in the state. In this

* Universidade de Pernambuco. Nazaré da Mata, Pernambuco, Brasil. Email: ana.dantas@, upe.br. ORCID: https://orcid.org/0002-9498-704X
\end{abstract}


sense, the construction of educational policies was conducted by managerial government in Pernambuco during the period investigated.

Keywords: Managerialism. Educational Policies. Education Workers. Citizen Participation.

\section{Introdução}

Este trabalho se configura como parte da pesquisa que realizamos, junto ao Sindicato dos Trabalhadores em Educação de Pernambuco - SINTEPE, para efeito de composição de nossa tese, cujo trabalho analisou a participação cidadã no contexto da reforma gerencial em Pernambuco no período 2010-2014. Objetivamos com este recorte, analisar como foram construídas as orientações que se encontram presentes na concepção das políticas de educação no governo de Pernambuco a partir da participação do Sindicato dos Trabalhadores em Educação de Pernambuco - SINTEPE, como entidade de representação dos trabalhadores em educação, na construção destas políticas. Para o alcance de tal propósito, cabe questionar: em que medida a racionalidade comunicativa foi capaz de contrapor-se ao protagonismo de gestão do modelo gerencial em Pernambuco através do SINTEPE na construção participativa da política na educação?

A pesquisa justifica-se com base na primordialidade da reflexão sobre a relação estado, governo e a participação social, no âmbito das mudanças estruturais do século XX no domínio da reestruturação produtiva e governança do estado que orquestram a concepção de educação na contemporaneidade ${ }^{1}$. A mudança no modelo do estado burocrático ao gerencial, no bojo de uma concepção ideológica de dimensão globalizada, assume a necessidade de conceber uma Aprendizagem ao Longo da Vida, em oposição a uma concepção social e humanista de educação permanente (CAVACO, 2008). Nesse sentido, a educação apresenta uma intencionalidade de reforço e reafirmação aos preceitos neoliberais com objetivos voltados para o mercado. Analisar o papel do SINTEPE na construção das políticas públicas educacionais é reconhecer a importância da participação cidadã bem como a relevância da participação dos profissionais de educação no contexto. Entendemos a participação como dimensão de mediação

1 A pesquisa aborda o período do governo Eduardo Campos (2010-2014) em Pernambuco, mas o Governador Paulo Câmara foi eleito em processo político sucessório do Partido Socialista Brasileiro - PSB, nesse sentido, a política de governo mantém continuidade. 
entre estado e sociedade, portanto, esta apresenta espaço em disputa no qual os trabalhadores têm histórico relevante na luta por autonomia em relação ao estado.

Os anos 1990 são marcados por nova intencionalidade de execução de políticas de estado no âmbito de uma lógica hegemônica de proporções globalizadas, que injunge a flexibilização, a reestruturação produtiva, a terceirização e a precarização como formas de dominação da sociedade por via da mercantilização da educação e do campo do trabalho. A competitividade contemporânea, as novas tecnologias, as modificações na administração estatal e empresarial vêm interferindo nas relações de representação sociais e sindicais.

No Brasil, as mudanças iniciaram-se no governo Collor de Melo e foram desenvolvidas nos governos subsequentes até a presente data, assim, este projeto encontra-se em curso no estado. Um dos desafios contemporâneos, ao intentar romper, se sobrepor e superar o modelo de desenvolvimento, consiste em problematizar o entendimento sobre a dimensão da participação cidadã como concepção de construção coletiva de políticas, e, neste construto, nosso trabalho peregrina.

A lógica da participação cidadã presente neste trabalho se ancora na teoria da racionalidade comunicativa de Habermas (2012) que encontrou uma forma de dar continuidade à crítica da razão instrumental. Para Habermas, a estrutura comunicacional na relação intersubjetiva visando ao entendimento, o que vai ao encontro da racionalidade instrumental cujas ações são dirigidas a determinados fins. Ao adotarmos essa dimensionalidade, apostamos na emancipação como processo de rompimento com a dominação.

A pesquisa foi realizada na base da gestão do SINTEPE e para efeito de análise da coleta dos dados passaremos a identificá-los por 'sujeito de pesquisa', por meio da letra 'S', como garantia do sigilo. As entrevistas seguiram roteiro semiestruturado, foram gravadas com autorização prévia dos(as) entrevistados(as) e às comunicações transcritas receberam tratamento com base no conteúdo das comunicações, com o objetivo de não se afastar do objeto de pesquisa. (BARDIN, 1977).

\section{O estado moderno, a autoridade gerencial e os trabalhadores em educação}

A nova gestão pública protagonizada pelo governo brasileiro na década de 1990 reuniu esforços para minimizar o tamanho do estado no seu poder de atuação e na diminuição de seus gastos, a partir do Plano Diretor de Reforma 
Administrativa do Estado - PDRAE sob a orientação do então ministro Bresser Pereira em 1995. A nova racionalidade sistêmica favorece a eficiência, eficácia, produtividade do mercado em sistema de regulação e controle com metas, monitoramento de desempenho, responsabilização, avaliação, bonificação, cuja justificação falaciosa permeia o campo da superação da inflexibilidade burocrática, presente no estado de bem-estar, e da participação (CAVALCANTI, 2011, 2011a, 2015, 2016).

As novas diretrizes do capital induzem que as formas organizacionais nos setores econômicos adiante da emersão da reestruturação produtiva e das novas tecnologias, acompanham novos processos como flexibilização da produção, novos tipos de contratos, compromissos com a terceirização e com a informalidade, entre outros. A educação nesse contexto tem sobre si grande responsabilidade de reformular seus currículos, definir metas, monitorá-las e conquistar resultados, a fim de atender essa nova demanda no campo do mercado.

Valendo-se de nova concepção ideológica, as concepções das organizações internacionais como Organização das Nações Unidas para a Educação, a Ciência e a Cultura - Unesco (2015), Organização para Cooperação do Desenvolvimento Econômico - OCDE (2015) e União Europeia - UE (2002) alinhadas às objetivações das organizações financeira (a exemplo do Banco Mundial), investem na educação pelo contributo desse campo ao desenvolvimento econômico (CAVACO, 2008), para isso deslocam o foco da educação permanente à Aprendizagem ao Longo da Vida. Ainda apresentam escopo de uma educação um caráter de desenvolvimento sustentável com foco na equidade e no mercado de trabalho. Gera-se com isso um arcabouço ideológico que inclui o culto às especificidades, em contraposição à universalidade e forte apelo à cultura da gestão na formação do ethos moderno. Alves et al (2014) alega que a expressão 'ao longo da vida' é assumida por tais organizações como estratégia do capitalismo para assegurar as vantagens competitivas de mercado. Essa concepção adentra no alicerce curricular e na definição das competências ${ }^{2}$ para uma qualidade voltada ao mercado, e com isso invade as bases de reprodução do modus operandi vivendi do capital: educação e trabalho. A literatura a respeito do período da Reforma Gerencial (ABRÚCIO, 1977; BALL, 2005; BIZERRA, 2008; CAVALCANTI, 2011; MOTTA, 2002; PEREIRA, 2002/2007/ 2008; SECCHI, 2009) evidencia que há compromissos e aderências a esta internacionalmente, coincidindo, inclusive, com definições mais severas no controle da ordem econômica e consequentemente política.

2 Para Unesco (1996), os pressupostos que envolvem qualidade na educação ao longo da vida, devem compor base curricular para o desenvolvimento humano e estão sob a base de quatro pilares definidos como: aprender a conhecer, a fazer, a viver junto e a ser. 
As políticas públicas e educacionais tiveram reflexo desde as novas terminologias (diretor $X$ gestor; cidadão $X$ cliente) no aparato administrativo com desenvolvimento do culto à responsabilização e ao conceito de qualidade na educação. A qualidade regulatória está identificada nas metas traçadas no campo da racionalidade sistêmica e o seu desempenho é o seu significado. Refletir sobre essa questão é ponderar sobre: i) o esvaziamento dos espaços públicos deliberativos; ii) as condições de trabalho que se impõem e iii) à organização individual. Essas implicações estão impressas na organização da sociedade no incentivo à competição 'no' e para 'o' mercado. Na educação e nas políticas públicas, o apelo ao privado e ao mercantil são facilmente identificados quando se bonifica o sucesso e quando se castiga pela não responsabilidade com os compromissos ${ }^{3}$ assumidos com as metas da gestão. Um sofisticado planejamento estratégico define as metas para a qualidade da educação nas avaliações internacionais e nacionais endereçadas para determinados sistemas (Exame Nacional do Ensino Médio - ENEM, Sistema Nacional de Avaliação do Ensino Superior - SINAES, Exame Nacional de Desempenho de Estudante - ENADE. Índice de Desenvolvimento da Educação Básica -IDEB, Programme for International Student Assessment $t^{4}$ - PISA, entre outros). A falácia da participação é contradita no modelo de gestão centralizado. Por essa razão, o planejamento da gestão não é matéria de negociação, modificação ou ressignificação por parte de qualquer sujeito que não faça parte do grupo gestor (CAVALCANTI, 2011, 2011a, 2015).

Perroni (2013) identifica algumas características do modelo:

As redes públicas têm buscado as parcerias como forma de atingir a tão almejada "qualidade da educação" imposta pelas avaliações e ditadas por uma lógica mercantil. Verificamos que, entre as principais implicações da parceria para a gestão democrática da educação, está a diminuição da autonomia do professor, que entre outros fatores fica minimizada, desde quando recebe o material pronto para utilizar em cada dia na sala de aula e tem um supervisor que verifica se está tudo certo, até a lógica da premiação por desempenho, que estabelece valores como o da competitividade entre alunos, professores e escolas [...]. A outra questão diz respeito às metas estabelecidas, que passam a dar mais ênfase ao produto final e não mais ao processo, como é característica da gestão democrática[...] (PERRONI, 2013, p. 248, grifos nossos).

3 Nas políticas educacionais em Pernambuco existe um Termo de Compromisso definido pela Gestão e entregue ao gestor das Unidades Escolares.

4 Programa Internacional de Avaliação de Alunos - PISA 
A autonomia da gestão sobrepõe a do professor que passa a conduzir o ensino sob as metas estabelecidas em currículo definido. Essa condução é monitorada ${ }^{5}$ e para tal realização o professor é recompensado pela entrega do produto final. Essa lógica vem sendo desenvolvida sob uma égide de naturalização do nexo dominante. $\mathrm{O}$ discurso da liberdade individual e o da competição estão a construir valores simbólicos de autonomia do sujeito por empreendedorismo e responsabilidade e sucesso nas decisões de gestão, como se proprietário fosse dos meios de produção. Atrelado a essa questão, o processo de privatização do público na educação vem sendo progressivamente instaurado e os limites dos docentes diante da reprodução de tal lógica é eminente. O mundo do consumo invadiu o mundo da educação onde estado é menos e mercado, mais. A resistência ao culto do individual e o fortalecimento da cultura da participação são no mínimo alternativas a colocar-se na contramão desse modelo.

Em Pernambuco, o sindicato prevê em seu estatuto: "propor alternativas para solucionar problemas da educação no Estado". (SINTEPE, 2008). Como órgão de representação da categoria profissional ou diferenciada, ou ainda se patronal, da categoria econômica, esse agrupamento existe para defesa de interesses que lhes são próprios. Seu poder de representação é privado, no diálogo com sua base e administrativo nas relações com o estado ao exercer seu poder de denúncia ou fiscalizar as ações públicas.

Do ponto de vista do trabalho, as investidas neoliberais privilegiaram o fenômeno da terceirização, que arrolado à flexibilização, vem desmontando os direitos trabalhistas conquistados com a Consolidação das Leis Trabalhistas $\mathrm{CLT}^{6}$. O movimento sindical, emergido nos anos 1980 no Brasil, após profundos embates e lutas no período militar enfrenta nova reorganização do trabalho dos anos 1990, apresentando fragilidade nas relações diante da desregulamentação da economia com demissões em massa, novas formas contratuais, flexibilização, informalidade, terceirizações e inserção de novas tecnologias. Nesse ritmo, os trabalhadores em educação exercem suas atividades profissionais de forma intensificada e precarizada ${ }^{7}$ em razão do governo que encobre a que veio de forma sutil e acentuada.

5 Em Pernambuco esse monitoramento é realizado pelo Técnico Educacional, cuja função foi instituída pela Lei Complementar $\mathrm{n}^{\mathrm{o}} 112 / 2008$.

6 No Brasil, a política gerencial avançou sob a legenda do Partido da Social Democracia Brasileira-PSDB e Partido dos Trabalhadores - PT. Atualmente o Presidente Michel Temer reafirma esta política. Um de seus efeitos no campo do trabalho repercute com o novo texto da Reforma Trabalhista, aprovada pelo Congresso Nacional em 2017.

7 A precarização é identificada na pesquisa por integrantes da gestão do SINTEPE. Estudos comprovam a assertiva e uma das referências é a tese de doutoramento de Mendes (2005) que identifica a síndrome do Burnout em Professores do Recife. 
Por essas convicções, cabe questionar: em que medida a racionalidade comunicativa foi capaz de contrapor-se ao modelo gerencial em Pernambuco no período de 2010 a 2014, por meio do SINTEPE sob a gestão de governo do Partido Socialista Brasileiro - PSB?

\section{O diálogo silenciado em Pernambuco por ofensiva do estado moderno}

Nesta seção pretendemos aclarar as ações do SINTEPE com base na análise dos dados onde focaremos em três dimensões participativas de formação de políticas educacionais: os canais de comunicação, as formas de diálogo e as estratégias de intervenção na construção coletiva dessas políticas.

Elucidando sobre os canais de comunicação, o sindicato informou que houve em Pernambuco no período de 1995 a 1998 um breve período de discussão pública, com fins a contribuir com a construção da política educacional do estado. Conforme S: "Na época do governo Miguel Arraes [...] nós conseguimos construir um periodo fértil de elaborar as políticas educacionais dentro do espaço da Secretaria de Educação do Estado - SEE”. Nesse sentido, o entrevistado reconhece a possibilidade de espaço de discussão na esfera governamental para formulação da política e completa definindo os avanços conquistados no período, a saber: o Estatuto do Magistério e o Plano de Cargo e Carreiras - PCC.

O sujeito critica a descontinuidade política assumida no governo posterior e identifica o início da educação gerencial a partir de contratos com a Fundação Getulio Vargas, Fundação Roberto Marinho e Instituto Airton Senna. Percebemos que a concepção administrativa gerencial, ao utilizar campos híbridos incluindo o público e privado, implica na despolitização da esfera pública inibindo o exercício participativo e transferindo-o para o campo institucional.

A expectativa de novo campo de forças políticas foi gerada com a candidatura do pré-candidato do Partido Socialista Brasileiro - PSB ao governo estadual $^{8}$, no entanto, afirma S: “[...] para nossa surpresa, a partir do momento que ele foi eleito, não houve mais nenhum tipo de articulação com o sindicato, no sentido da formulação das políticas". Esta assertiva denota que o governo não buscou a base dos trabalhadores a fim de montar ações de governo. Reitera S: "[...] no dia 02 de janeiro de 2007 [...], entregamos um dossiê completo ao

8 A pesquisa abrange o segundo período de governo de Eduardo Campos (2010-2014). A gestão de Eduardo Campos em Pernambuco teve início em 2007. Nesse sentido, a expressão do sujeito da pesquisa remonta ao início de seu governo. 
Secretário na época, [...] e reivindicamos resgatar a política educacional a partir do espaço da SEE, mas, não fomos ouvidos [...] o governo decidiu continuar o processo de contratar empresas privadas para fazer as políticas públicas de Educação". As críticas do sindicato ao governo apontam uma quebra de condução no tocante a acordos firmados sobre os espaços de diálogo e no campo comum do entendimento.

De acordo com Botler (2006), o que acontece na modernidade é que a lógica sistêmica não considera o paralelo de formulação de novos valores necessários à incorporação de novas práticas. A regulamentação da sociedade civil que pode ser desenvolvida a partir da consolidação de instrumentos e instâncias de participação democrática deve potencializar suas ações de entidade copartícipe das ações políticas, portanto, públicas, cujo objetivo seria, em tese, a construção de ações voltadas à sociedade.

Os espaços de participação e discussão identificados pelos sujeitos da pesquisa se resumem ao congresso da categoria e a conferência de educação. "S" explica: "E se tem espaço criado pelo próprio governo, não existe nenhum que dê as condições para você pensar, elaborar, aplicar e avaliar as políticas. Por quê?? Porque tudo vem como pacote já pronto. [...] é uma política de submissão[...]" A crítica reflete a centralidade administrativa do modelo.

Conforme explicita o sujeito S: "Na verdade, o governo impõe uma política educacional [...] pelo fato de não termos sido escutados, enquanto entidade representativa da categoria, o desafio é correr atrás dessas políticas [...]. ” $\mathrm{O}$ significado do 'correr atrás' configura-se na objetivação de se fazer ouvir, de ir refletir sobre as ações governamentais anunciadas, demonstrando assim que a prioridade da ação deve considerar as condições objetivas e necessidades de um poder local.

Sobre a política em Pernambuco:

Na verdade, as queixas da categoria são enormes [...] no caso do bônus, nós não defendemos o bônus, nós defendemos que o professor ele tenha um salário decente. [...] No tocante à gestão das escolas, nós temos uma proposta de gestão democrática que não passa simplesmente pela eleição do diretor da escola, mas passa pelo fortalecimento do Conselho Escolar [...]. A questão das metas estabelecidas pelo governo, nós também temos uma série de restrições uma vez que as cobranças são feitas [...] que nas condições que são oferecidas elas são impossíveis de serem atingidas. [...] o professor fica sob uma pressão tremenda, até com problemas para a saúde, [...] porque as exigências são tamanhas e as condições para que o professor cumpra as metas estabelecidas, elas são inversamente proporcionais. (S, grifos nossos) 
A organização sindical indica que o comprometimento social está no caminho inverso e este se configura no fortalecimento dos conselhos escolares na Rede Estadual. É importante lembrar que o bônus é temporário e não incorporado ao Plano de Cargos e Carreiras (PERNAMBUCO, 1998), o que significa reconhecer uma política de governo temporária, não estruturante. Sobre a pactuação de metas no âmbito da gestão, ao não considerar os instrumentos de diálogo e participação nas instâncias do sistema de ensino revela que o governo não apresenta propostas que indique o fortalecimento dos órgãos colegiados instituído na educação. No entanto, apesar do depoimento apontar que há proposta de fortalecimento da gestão democrática para a Rede de Ensino, não há evidências desta proposta está sendo trabalhada na esfera pública.

Investigando sobre a materialização do diálogo, conforme os relatos evidenciados, estes se concretizam nos espaços sociais do governo e em espaços externos de acordo com sua conveniência: “[...] o governo prefere contratar institutos e definir sua política educacional dentro de gabinetes fechados, muitas vezes distante da realidade da escola, do estudante e do professor.” (S). A não materialização do diálogo do governo com a sociedade anuncia as concepções ideológico-filosóficas de um modelo de gestão assumida politicamente na forma de governar o estado. $O$ enfrentamento a esta cultura, que designamos para efeito de compreensão, como a cultura do silêncio, passa por um acompanhamento e avaliação com proposição de uma moção democrática e participativa. Os espaços sociais de participação ao serem deslocados do governo sem finalidades deliberativas colaboram com a falácia da participação deixando ao poder governamental formas de anular os efeitos da representação social.

Para colaborar com tal argumento, os depoimentos caminham para esclarecer que o governo exerce a escuta. O espaço de materialização do diálogo se transformou em espaço de escuta e de acompanhamento a uma política que não se permite nascer de uma forma compactuada, consensuada, participativa e avaliada no coletivo dos sujeitos por ela envolvidos. Essa identificação aponta intencionalidades: o escutar como forma de estratégia legitimadora e a de isolar o lado questionador. Ao exercer a escuta de forma a inativá-la, o sindicato responde com o poder da denúncia sem, contudo, apresentar poder de intervenção. A estratégia da denúncia retrata a ausência de argumentos. A estratégia que o sindicato assume adiante da imposição dos programas de governo nos sinaliza para a fragilidade da representação no âmbito de assuntos que merecem ser avaliados no tocante ao seu efetivo alcance social com impacto na melhoria da qualidade das pessoas.

Em complemento ao que afirmou S, outro entrevistado aponta outros espaços de materialização da discussão e reflexão da execução da política: 
No estado nós temos participado de diversos conselhos [...] e a partir dai, nesses espaços, fazermos a defesa daquilo que nós construímos coletivamente como um modelo educacional que possa atender à sociedade pernambucana que, na verdade, está muito distante daquilo que nós temos hoje. (S)

A identificação da utilização de espaços de diálogo por meio da participação em Conselhos Setoriais encontra-se no limite de sua negação, até porque os conselhos setoriais estão sendo conduzidos a cumprir agenda meramente burocrática no estado gerencial no campo estudado. A formação de diálogo na política de educação, junto ao Conselho Estadual de Educação, no mesmo período, evidencia domínio da racionalidade sistêmica em detrimento à constituição de espaço de diálogo para o mesmo fim (CAVALCANTI, 2015).

Identifica o entrevistado:

[...] O Sindicato investe na comunicação, investe na formação de seus dirigentes, investe na formação de sua base, busca manter um diálogo com a sociedade através dos diversos canais que nós colocamos aqui, mas na verdade, o resultado em termos de mobilização, o resultado em termos de apropriação pela sociedade de tudo isso, ele ainda é muito pequeno. [...]. (S)

A limitação de alcance à sociedade restringe a intervenção no âmbito de sua esfera. É fundamental o entendimento de que as questões objetivas de vida requerem um trato educativo em suas diferentes nuances, o que requer o exercício da reflexão nos espaços públicos sobre determinadas questões que são inerentes à comunicação intersubjetiva no processo coletivo de discussão. A comunicação aqui expressa não se utiliza da fundamentação argumentativa capaz de provocar o entendimento e o consenso, por esta questão apresenta-se frágil em resultado.

Netto (1980) reflete que os direitos de cidadania e a luta pela democracia apresentam-se como instrumentos da classe dominada contra o sistema de opressão a que estão submetidas. A abertura de possibilidades no âmbito do direito é o retrato de que as oportunidades não são iguais. $\mathrm{O}$ que nos cabe aqui refletir é o sentido da mediação na conquista desses direitos valendo-se da cidadania. A coletividade ao se apropriar do conhecimento e da racionalidade comunicativa, engendrará poder próprio e favorecerá à sociedade uma maior possibilidade de 
interlocução rumo a conquistas e avanços por meio da participação cidadã. O movimento sindical apresenta o discurso do estabelecimento da autonomia em sua própria resistência coletiva, mas nos parece que não dispõe de um campo de força suficiente para combater a instituição reguladora à qual se opõe. Por essa perspectiva, Hayek (1983) argumenta que o liberalismo é incompatível com uma democracia ilimitada. $\mathrm{O}$ estado liberal ou regula os poderes da democracia direta, ou se deixa sucumbir para além de outra ordem societária.

A problemática da avaliação do modelo gerencial é refletida. "S" evidencia:

O SINTEPE vem tentando até hoje entender e compreender a lógica da avaliação por luzes. A vermelha avisa que a escola não alcançou as metas, a amarela avisa que na escola as metas estão em andamento e a vermelha indica que a escola não alcançou as metas estabelecidas. $O$ SINTEPE não sabe como é respondido esse questionário com perguntas repetidas e a coerência nas respostas. [...] Nesse caso o governo não é transparente e não oferece informação ao SINTEPE, porque, por exemplo, tem escola que tem pontuação zero e recebe o prêmio. Essa política é de grande prejuizo para Educação de Pernambuco - PE.

A denúncia prescreve a regulação do estado sobre o trabalho do professor por intermédio de percentuais a maior em seu salário, por meio da realização de tarefas extras, sob condição de recebimento da bonificação. É notória a crítica ao governo, porém, o poder de interferência, nesse caso, não se encontra no governo. O poder de argumentação do sindicato com os professores deveria culminar em mobilização e consenso e provocar diálogo sobre a execução no campo da decisão governamental como enfrentamento à política à qual condena. O limite pode permear: ausência de diálogo na própria base sindical; política de não valorização profissional evidenciando a bonificação como política compensatória; cultura da naturalização da política gerencial no estado.

O governo utiliza-se de um poder instrumental que age no sentido de dificultar a criação de canais e/ou espaços de participação e os utiliza no campo da informação como estratégia instrumental de inibição de diferentes formas de diálogo. Esse poder incide na desmobilização na base dos profissionais da educação dificultando seu poder de intervenção. O discurso da participação ou escuta sem impacto se encontram vigentes na mediação de cidadania no estado. Em Pernambuco. os estudos de Santos (2006), Arruda (2011), Cavalcanti (2011; 2011a), Andrade (2012) e Botler et al (2012) apontam a centralização das decisões do estado enfraquecendo os mecanismos de democratização e controle social. 
As estratégias de intervenção estão sendo mal interpretadas. A categoria diálogo está sendo vista pelo SINTEPE como sinônimo de negociação. Stoll (2007) sinaliza que, para o sindicalismo, não se pode pensar num sistema sindical e no direito de greve que não admita a negociação prévia e coletiva de trabalho como decorrência lógica do direito à liberdade sindical que deve ser exercida amplamente. De certa forma, a negociação sob esta perspectiva requer diálogo entre partes de interesses opostos, no entanto, o diálogo ao qual nos referimos é categoria ampla que vai além da negociação salarial. Os mecanismos de participação aqui referidos incorporam os assuntos de educação de uma maneira geral que requerem discussão, reflexão, conhecimento, consenso, entre outras dimensões já mencionadas, para a formulação da política pública de educação.

A cidadania na modernidade convive em processo dinâmico e contraditório. Se por um lado a ampliação de direitos - não adquiridos ou suprimidos pelo estado minimizado - se prolifera em larga escala através de movimentos participativos da sociedade civil, por outro as manifestações não se traduzem em políticas que materializem os anseios populares. Essa questão nos possibilita refletir que as relações de produção no modelo neoliberal contribuem para manter essa contradição.

Para S: "[...] nós temos dificuldade de indicar e garantir aquilo que nós apontamos como política educacional e o governo, além de não aplicar, a [política] que tem que é "capenga", deixa a desejar e há toda essa dificuldade estabelecida nesse processo". Esta passagem explicita que a racionalidade sistêmica se sobrepõe às formas insipientes de participação do Sindicato na perspectiva de discutir a política educacional do estado e por este argumento a implantação do modelo gerencial vem fortalecer a racionalidade sistêmica assumindo fortemente o sentido do poder decisório. O exercício da escuta é uma estratégia segura de planejamento e qualidade na ação sistêmica como contraponto de inibição de estratégias de intervenção.

A relação de poder que se estabelece em torno de objetivos estratégicos de grupos oponentes requer força nos movimentos mobilizatórios, argumentos e consenso. Esse movimento não é fácil, principalmente quando não existe a cultura da participação na sociedade aliada ao modelo administrativo vigente de estado que apresenta a participação sob forma de legitimação das ações.

\section{Considerações finais}

A participação cidadã no domínio da racionalidade dialógica faculta as relações intersubjetivas que levam ao conhecimento, à formação de opinião, 
à validação, à avaliação, ao consenso e à tomada de decisão (HABERMAS, 2012). O novo modelo gerencial não oportuniza o diálogo na esfera pública porque requer governança.

Habermas (2012) nos oferece categoria de análise que nos possibilita caminhar na complexidade da sociedade globalizada sob a concentração do capital na perspectiva de encontrar formas de deliberação em assuntos sociais que estão no limite da exclusão e do direito. O paradigma do conhecimento, em relação intersubjetiva da comunicação, é um passo considerável para uma tomada de decisão e reversão de uma ideia estabelecida. A crítica não deve ser esvaziada de proposição. A superação requer um contraponto com a política, o estado, os movimentos sociais para um exercício de cidadania para além do consumo. Há dificuldades na ofensiva neoliberal, mas há campo de possibilidades.

O projeto habermaseano não está condicionado a uma classe, a um sistema, a uma sociedade ou a uma época, mas à humanidade, na medida em que estes assumem competência comunicativa. No atual processo histórico ainda não dispomos dessa competência, mas o pressuposto do campo da ação está na potencialidade humana de contraposição pela participação cidadã para as ressignificar. O desenvolvimento da intersubjetividade com base na ação comunicativa é uma possibilidade de resposta na contramão do projeto hegemônico do mercado.

\section{REFERÊNCIAS}

ABRUCIO, F. L. O impacto do Modelo Gerencial na Administração Pública. Um breve estudo sobre a experiência internacional recente. Cadernos ENAP, Brasília: Vera Lúcia Petrucci, n. 10, 1997.

ALVES, N.; CANÁRIO, R.; MELO, A. de; FRAGOSO, A.; CAVACO, C.; GUIMARÃES, P. Pensar a Educação. Aprender sempre. Educação da população adulta para a cidadania participativa e responsável. Lisboa, 2014. Disponível em: $<\mathrm{http} / /$ fundacao-betania.org/ges/Educacao2015/PENSAR_A_EDUCACAO_EDUCACAO_DE_\%20 ADULTOS.pdf $>$. Acesso em: $1^{\circ}$ ago. 2017.

ANDRADE, E. F. de. Relação entre Gestão Sistêmica e Democratização da Educação no Município: o papel do Conselho Municipal de Educação em foco. In: SEMINÁRIO REGIONAL DE POLÍTICA E ADMINISTRAÇÃO DA EDUCAÇÃO DO NORDESTE, 2012, Recife. Cadernos ANPAE. Fortaleza, Ceará, Brasil: Biblioteca ANPAE, 2012. v. 13. p. 1-18.

ARRUDA, C. A. de. Gestão Democrática da Educação: um estudo da realidade do agreste pernambucano, 2011. Disponível em: $<$ http://www.fundaj.gov.br/images/stories/ epepe/III_EPEPE/gestao_democratica_da_educacao.pdf $>$. Acesso em: 23 ago. 2017. 
BALL, S. J. Profissionalismo, gerencialismo e performatividade. Cadernos de Pesquisa, v. 35, n. 126, p. 539-564, set./dez. 2005.

BARDIN, L. Análise de conteúdo. Lisboa: Edições 70, 1977.

BIZERRA, M. da C. Gestão Educacional: fusão de horizontes da democracia liberal à democracia procedimental. 2008. Tese (Doutorado em Educação) - UFPB, Paraíba, 2008.

BOTLER, A. M. H. A Escola como Organização Comunicativa. GT: Sociologia da Educação/n. 14. ANPED, 2006. Disponível em: <http://www.anped.org.br/sites/default/ files/gt14-1816-int.pdf>. Acesso em: 27 ago. 2017.

BOTLER, A. M. H.; LIMA, M. S. de.; DIAS, W. A. Gestão Democrática: implicações da participação da comunidade para a melhoria da organização da escola. Recife: UFPE, 2012.

CAVACO, C. Adultos pouco escolarizados. Diversidade e interdependência de lógica na formação. 2008. Tese (Doutorado em Ciências da Educação) - Universidade de Lisboa, 2008. Disponível em: $<$ http://repositorio.ul.pt/bitstream/10451/972/1/17505_ulsd_re286_ TD_Carmen_Cavaco3.pdf>. Acesso em: 27 fev. 2017.

CAVALCANTI, A. C. D. Participação cidadã no contexto da reforma administrativa do Estado de Pernambuco. 2015. Tese (Doutorado em Educação) - UFPE, 2015.

CAVAlCANTI, A. C. D. Orçamento Participativo do Recife: avaliação do grau de implementação das ações aprovadas para o Setor de Educação no Exercício do Ano de 1999. UFPE, 1999.

CAVAlCANTI, A. C. D. Programa de Modernização da Gestão Pública/ Metas para a Educação / 2007-2010: análise sobre a "Gestão Democrática" da educação de Pernambuco. João Pessoa, 2011.

CAVALCANTI, A. C. D. A concepção de gestão democrática no Programa de Modernização da gestão educacional em Pernambuco (2007/2010) na percepção dos gestores educacionais do Recife, Região Metropolitana e Zona da Mata. Cadernos ANPAE, v. I, p. 01-13, 2011a.

CAVAlCANTI, A. C. D. Políticas Públicas: Controle e Qualidade. In: FALCÃO, P. H. de B.; SCHURSTER, K. (Org.). Educação, política e outras histórias. Rio de Janeiro: Autografia - EDUPE, 2016.

HABERMAS, J. Teoria do Agir Comunicativo. Racionalidade da ação e racionalização social. v. 1. Traduzido por Paulo Astor Soethe. Sobre a crítica da razão funcionalista. v. II. Traduzido por Flávio B. Siebeneichler. São Paulo: WMF Martins Fontes, 2012.

HAYEK, F. A. O caminho da servidão. Tradução por Anna Maria Capovilla, José Ítalo Stelle e Liane de Morais Ribeiro. 5. ed. Rio de Janeiro: Instituto Liberal, 1993. 
MENDES, M. L. M. A tradução do fracasso: Burnout em professores do Recife. 2015. Tese (Doutorado em Educação) - UFPE, Recife, 2015.

MOTTA, F. C. P.; VASCONCELOS, I. F. G. Teoria Geral da Administração. São Paulo: Pioneira Thomson Learning, 2002.

NETTO, J. P. Notas sobre democracia e transição socialista. São Paulo: Ciências Humanas, 1980. (Temas de Ciências Humanas, v. 7)

OCDE. Brazil Policy Brief, 2015. Disponível em: <https://www.oecd.org/policy-briefs/ brasil-capacitacao-e-educacao-para-o-crescimento.pdf>. Acesso em: 30 jul. 2017.

PEREIRA, L. C. Reforma do Estado para a cidadania: a reforma gerencial brasileira na perspectiva internacional. São Paulo: Editora 34, Brasília: ENAP, 2002.

PEREIRA, L. C. Burocracia pública e reforma gerencial. Revista do Serviço Público de 1937 a 2007, número comemorativo dos 70 anos. p. 29-48, 2007.

PEREIRA, L. C. B. O modelo estrutural de gerência pública. Revista Brasileira de Administração Pública, São Paulo, v. 42, p. 391-410, 2008.

PERNAMBUCO. Lei n. 11.559, de 10 de junho de 1998. Institui o Plano de Cargos e Carreiras - PCC, do Quadro Permanente de Pessoal do Sistema Público Estadual de Educação e Esportes e determina providências pertinentes. Diário Oficial do Estado de Pernambuco, Recife, 11 jun. 1998.

PERONI, V. M. V. As relações entre o público e o privado nas políticas educacionais no contexto da Terceira Via. Currículo sem Fronteiras, v. 13, n. 2, p. 234-255, maio/ago. 2013. Disponível em: < http://www.curriculosemfronteiras.org/vol13iss2articles/peroni. pdf>. Acesso em: 22 ago. 2017.

SANTOS, A. L. F. dos. Gestão Democrática da Escola: bases epistemológicas, políticas e pedagógicas. ANPED, 2006. Disponível em: <http://29reuniao.anped.org.br/trabalhos/ trabalho/GT05-2114--Int.pdf>. Acesso em: 23.08.2017.

SECCHI, L. Modelos Organizacionais e Reformas da Administração Pública. Revista da Administração Pública, v. 43, n. 2. Rio de Janeiro, mar./abr., 2009. Disponível em: ,http://www.scielo.br/pdf/rap/v43n2/v43n2a04.pdf>. Acesso em: 23 ago. 2017.

SINTEPE. Estatuto do Sintepe. Recife, 2008. Disponível em: <http://www.sintepe.org. br/estatuto_sintepe.pdf>. Acesso em: 23 ago. 2017.

STOLL, L. B. Negociação coletiva no setor público. São Paulo: Ltr, 2007.

UNESCO (Org.). Educação - um tesouro a descobrir. Relatório para a UNESCO da Comissão Internacional sobre Educação para o século XXI. Porto: Ed. Asa, 1996.

UNESCO (Org.). Recomendações sobre Aprendizagem e Educação de Adultos, 2015. Disponível em: <http://www.unesco.org/new/pt/brasilia/about-this-office/single-view/ news/recommendation_on_adult_learning_and_education_2015_in_port/ $>$. Acesso em: $1^{\circ}$ ago. 2017. 
UNIÃO EUROPEIA. Educação e formação na Europa: sistemas diferentes: objectivos comuns para 2010. Comissão Europeia. Direcção-Geral da Educação e da Cultura. Luxemburgo: Serviço das Publicações Oficiais das Comunidades Europeias, 2002.

Texto recebido em 11 de outubro de 2017 Texto aprovado em 25 de dezembro de 2017. 